\title{
DHT - Diary Handy Terminal - for Evaluating Fluctuations in Patients with Parkinson's Disease (PD)
}

\author{
M.M.Pinter, R.J.Helscher and H.Binder \\ Neurological Hospital Maria Theresien Schlössel \\ Vienna, Austria
}

\begin{abstract}
In order to permit immediate evaluation of fluctuations in advanced PD and corresponding modification of drug adminstration we developed a software package running on an Epson Handy Terminal.

In a prospective study of $38 \mathrm{PD}$ patients we investigated the improved data evaluation and statistical evaluation of fluctuations registered by DHT as compared to hand-written entries. It was our main objective to investigate in principle the possibility of using a computer-assisted technique for the documentation of oscillations in Parkinson's disease.

The data acquired in the two different ways were evaluated for all 38 patients. As regards accuracy of data acquisition, DHT was superior to the handwritten version. Moreoever DHT also allowed a check of acutal drug intake time to the second. As regards the relationship between duration of drug action and occurence of fluctuations or dyskinesia, DHT provides rapid information for a modification of the therapeutical time schedule.
\end{abstract}

\section{Introduction}

With progression of Parkinson's disease, which phenomenologically does not present a straight course, motor fluctuations occur again and again; these are subdivided into short-term (seconds up to minutes), medium-term (hours) and long-term (days up to weeks) fluctuations. Parkinsonian symptoms fluctuate even without treatment, but they increase during long-term therapy and may develop into a major therapeutical problem (1-8). The initial therapeutic efficacy of oral Ldopa application in parkinsonian patients, therefore breaks down in the course of the first three two five years of treatmen $(9,10)$. "On-off" phenomena of motor symptoms occur in approximatelly $50 \%$ of parkinsonian patients receiving L-dopa and thus represent a limiting factor in the treatment (11).

It is well known that fluctuations of motor response - partly drug-induced - may occur in advanced stages of $\mathrm{PD}$, which require a change of treatment strategies (12-18). A verified and generally accepted explanation for the reduction of drug efficacy does not yet exist. It might be connected with the decreased transformation of L-dopa to dopamine and the reduced storage capacity of 
dopamine due to progressive loss of dopaminergic neurons (19). Blockage of the L-dopa passage by accumulation of the metabolite 3-O methyl dopa is also being considered. It has been demonstrated that patients with a high plasma ratio of OMD/L-dopa have significantly more fluctuations (20-24).

Such fluctuations, either corresponding to drug intake or occurring independently, are usually documented every hour or every fifteen minutes by hand written entries in a motor diary, which serves as a basis for treatment modification and better symptom control. The only disadvantage of this method is the limitation in time of such a form of documentation. In order to overcome this obstacle and to permit immediate evaluation of fluctuations and corresponding modification of drug administration we developed a software package running on an Epson Handy Terminal.

We designed a comparative study of 38 parkinsonian patients demonstrating the improved data evaluation and statistical evaluation of fluctuations registered by developed a software package running on an Epson Handy Terminal as compared to hand-written entries.

\section{Method}

We have developed a software package called Diary Handy Terminal (DHT), written in Basic, which permits registration of "off"-, "on"- and "on" phases with dyskinesia while the patient is awake or is asleep as well as drug intake and meal times.

In principal, we differentiate two parts of the DHT programme: a module called "patients" to which only the examiner has access for recording demographic data such as name, birth date, onset of the disease, Hoehn and Yahr staging in the "on" phase, drugs prescribed and prescribed times of drug intake, - and a module called "service" to which the patient has access. Here the fluctuations during waking, drug intake and meal times are entered. The software package runs on an Epson handy terminal, which the patient takes home for documentation purposes. The patient himself enters on this terminal all changes of motor response and drug intake with accuracy to the minute. At the next follow-up at the hospital the data are entered into the SQL data base and are used for graphic processing and statistical evaluation.

For the purpose of this study the patient receives a Diary Handy Terminal - DHT (version 2) as described above and a movement diary (version 1), into which he enters in hourly intervals any changes of motor response as well as the time of drug intake. The patients were carefully instructed in the handling of the Diary Handy Terminal and received a short training. Patients were requested to complete both 
documentations in parallel. The data acquired in two different ways were checked for their accuracy, informative value and practical relevance.

\section{Patients}

We enrolled in the present study exclusively patients with idiopathic Parkinson's disease with a verified history of fluctuations. The patient populations of a total of 38 includes 24 males and 14 females, aged 42 to 72 years (mean 58.9 years). Mean duration of the disease was 11.2 years (3.2 to 15 years), mean duration of L-dopa treatment was 8.7 years ( 3 to 14 years), and the mean L-dopa dose amounted to $970 \mathrm{mg}$. First fluctuations occurred on the average 5.4 years (2.7 to 10 years) prior to study enrolment. Demographic data, Hoehn and Yahr staging, additive medication with dopamine agonists, anticholinergics and deprenyl, and a breakdown of the type of fluctuations are given in table 1.

\begin{tabular}{|c|c|c|c|}
\hline age & 58,9 & \multicolumn{2}{|c|}{ (42-72) years } \\
\hline Hoehn \& Yahr stage & $\begin{array}{l}\text { - "on" } \\
\text { - "off" }\end{array}$ & $\begin{array}{l}1,7 \\
3,5\end{array}$ & $\begin{array}{l}(1-3) \\
(3-4)\end{array}$ \\
\hline duration of PD & & 11,2 & $(3,2-15)$ years \\
\hline $\begin{array}{l}\text { L-Dopa / duration } \\
\text { L-Dopa / dosage }\end{array}$ & & $\begin{array}{l}8,7 \\
870\end{array}$ & $\begin{array}{l}\text { (3-14) years } \\
(600-1300) \mathrm{mg}\end{array}$ \\
\hline $\begin{array}{l}\text { dopaminagonists } \\
\text { bromocriptine } \\
\text { lisuride } \\
\text { deprenyl } \\
\text { anticholinergic }\end{array}$ & & & $\begin{array}{l}14 \text { patients } \\
11 \text { patients } \\
21 \text { patients } \\
10 \text { patients }\end{array}$ \\
\hline $\begin{array}{l}\text { fluctuations / duration } \\
\text { Typ }\end{array}$ & $\begin{array}{l}\text { - wearing off } \\
\text { - komplex }\end{array}$ & 5,4 & $\begin{array}{l}(2,7-10) \text { years } \\
18 \text { patients } \\
10 \text { patients }\end{array}$ \\
\hline dyskinesia & $\begin{array}{l}\text { - peak of dose } \\
\text { - biphasic }\end{array}$ & & $\begin{array}{l}7 \text { patients } \\
4 \text { patients } \\
3 \text { patients }\end{array}$ \\
\hline dystonia & & & 4 patients \\
\hline
\end{tabular}

table 1: Demographic data: 38 patients (f: $14 ; \mathrm{m}: 24)$ with idiopathic Parkinson's Disease 


\section{Results}

The data acquired in the two different ways described above were evaluated for all 38 patients. As regards accuracy of data acquisition, DHT (version 2) was superior to the handwritten version. Version 1 permitted evaluation of changes in motor response in hourly intervals, while version 2 provided accurateness to the minute. Moreover version 2 also allowed a check of actual drug intake time to the minute (table 2 and 3).

\begin{tabular}{|l|c|c|}
\cline { 2 - 3 } \multicolumn{1}{c|}{} & version1 & version2 \\
\cline { 2 - 3 } \multicolumn{1}{c|}{} & hours & hours \\
\hline "OFF" & $\mathbf{4 , 5}$ & $\mathbf{5 , 1 2}$ \\
& $(1-6)$ & $(0,88-5,98)$ \\
\hline "ON" & $\mathbf{9 , 2}$ & $\mathbf{9 , 4 3}$ \\
& $(6-14)$ & $(6,22-13,98)$ \\
\hline DYSKINESIA & $\mathbf{2 , 3}$ & $\mathbf{2 , 1 2}$ \\
& $(1-4)$ & $(0.98-4,68)$ \\
\hline
\end{tabular}

table 2:Fluctuations during the day.

\begin{tabular}{|c|c|c|}
\hline & version 1 & version2 \\
\hline & minutes & minutes \\
\hline $\begin{array}{l}\text { time between } \\
\text { drug intake / "ON" }\end{array}$ & & $\begin{array}{c}31,2 \\
(12-57)\end{array}$ \\
\hline $\begin{array}{l}\text { time between drug } \\
\text { intake / DYSKINESIA }\end{array}$ & & $\begin{array}{c}27,3 \\
(16-34) \\
\end{array}$ \\
\hline $\begin{array}{l}\text { time between } \\
\text { drug intake / "OFF" }\end{array}$ & & $\begin{array}{c}187 \\
(58-222)\end{array}$ \\
\hline
\end{tabular}

table 3: Changes in motor response and relationship to drug intake.

As regards the relationship between duration of drug action and occurrence of fluctuations or dyskinesia, version 2 provides rapid information for a modification of the therapeutical time schedule. Version 1 on the other hand, which records fluctuations only in hourly intervals, allows only an approximate estimation of time relationships, even if the patient records drug intake to the minute (table 2).

From a practical point of view, version 2 is at first sight the more complicated procedure for the patient; however the majority of patients experience in the long run version 2 as an improvement, in particular since the accoustic signal, which 
reminds the patient that it is time to take the drug, is considered to be a positive aspect.

\section{Discussion}

There is no doubt that the diary handy terminal is superior to version 1 as regards data acquisition. The possibility of accurate evaluation of motor fluctuations reflected by drug intake opens the gate for better modification of drug therapy. It is possible to record rapidly principal data, such as onset and duration of action of the drug, in particular of L-dopa medication, which are not only determined by the progression of the disease but are also subject to individual flluctuations $(9,10)$. Moreover, the exact recording of time relationships between drug intake and occurrence of "on-off" phases or dyskinesia permits easy differentiation of the phenomenology of "on-off" phases and dyskinesia, which is an absolute necessity for adequate modificationof therapeutical strategies $(12,13,16)$.

Since the software programme is very comfortable for the user and very simple, it causes certainly no problems with patient compliance. Our experiences lead to the following two conclusions:

- First: patients who complete accurate movement diaries have no problems whatsoever with the DHT, or vice versa, patients who are unable to operate the DHT, are also unable to complete correctly handwritten movement diaries.

- Second: on the basis of survey diagrams and the automatic calculation of various phases over the day and the relationships between drug intake and onset of action, the physician is more competent when correcting therapeutical strategies. Certainly, further, in particular randomized long-term studies are necessary to substatiae the latter argument, which will clarify the question of therapeutic efficiency for the patient provided by the data acquired with the diary handy terminal.

The present study is intended as a pilot study. It was our main objective to investigate in principle the possibility of using an EDV-assisted technique for the documentation of oscillations in Parkinson's disease and furthermore to evalulate to what extent, DHT is superior to conventional techniques.

\section{References}

1. C.D. Marsden, J.D. Parkes: "On-off" effects in patients with Parkinson's disease on chronic levodopa therapy. Lancet 292-296 (1976) 
2. M.W.I.M. Horstink, J.C.M. Zijlmyns, J.W. Pasman et al.: Severity of Parkinson's disease is a risk factor for peak-of-dose dyskinesia. J Neurol Neurosurg Psychiatry 53, 224-226 (1990)

3. R.A.C. Roos, C.B. Vredevoogd, E.A. Vandervelde: Response fluctuations in Parkinson's disease. Neurology 40, 1344-1346 (1990)

4. A.E. Lang, K. Johnson: Akathisia in idiopathic Parkinson's disease. Neurology 37, 477-481 (1987)

5. M.A. Menza, J. Sage, E. Marshall et al.: Mood changes and "on-off“ phenomena in Parkinson's disease. Move Disord 5, 148-151 (1990)

6. N. Giladi, D Mc Mahon, S. Przedborski et al.: Motor blocks in Parkinson's disease. Neurology 42, 339-339 (1992)

7. J. Jankovic, F. Nour: Respiratory dyskinesia in Parkinson's disease. Neurology 36, 303-304 (1986)

8. R.J. Hardie, A.J. Lees, G.M. Stern: On-off fluctuation in Parkinson's disease. A clinical and neuropharmacological study. Brain 107, 487-506 (1984)

9. W.H. Poewe, A.J. Lees, G.M. Stern: Low-dose levodopa therapy in Parkinson's disease: a six year follow-up study. Neurology 36, 1528-1530 (1986)

10.M.R. Luquin, O. Scipioni, J Vaamonde et al.: Levodopa-induced dyskinesia in Parkinson's disease: clinical and pharmacological classification. Mov Disord 7 , 117-124 (1992)

11. A.J. Lees: The on-off phenomenon. J Neurol Neurosurg and Psychiatry. Special Supp. 29-37 (1989)

12.C.G. Goetz, C.M. Tanner, H.L. Klawans et al.: Parkinson's disease and motor fluctuation: long acting carbidopa/levodopa (CR4-Sinemet). Neurology 37, 875-878 (1987)

13.N. Quinn, J.D. Parkes, C.D. Marsden: Control of on/off phenomenon by continous intravenous infusion of levodopa. Neurology 34, 1131-1136 (1984)

14.S.T. Gancher, J.G. Nutt, W. Woodward: Response to brief levodopa infusions in parkinsonian patients with and without motor fluctuation. Neurology 38, 712-716 (1988) 
15. J.A. Obeso, M.R. Luquin, J.M. Martinez-Lage: Lisuride infusion pump: A device for the treatment of motor fluctuations in Parkinson's disease. Lancet $i$, $467-470$ (1986)

16. C.M.H. Stibe, A.J. Lees, P.A. Kempster, G.M. Stern: Subcutaneous Apomorphine in Parkinsonian on-off oscillations. Lancet 1, 403-406 (1988)

17. W.H. Poewe, B. Kleedorfer, F. Gerstenbrand, W.H. Oertel: Subcutaneous Apomorphine in Parkinson's disease. Lancet 1:, 943 (1988)

18.C.M.H. Stibe, A.J. Lees, G.M. Stern: Subcutaneous infusion of apomorphine and lisuride in the treatment of parkinsonian on-off fluctations. Lancet 1,871 (1987)

19.G.F. Wooten: Neurochemistry. In: W.C. Koller: Handbook of Parkinson's disease. New York, Basel: Marcel Dekker Inc. pp. 237-251 (1987)

20.D.B. Calne, M.J. Zigmond: Compensatory mechanisms in degenerative neurologic neurologic diseases. Insights from parkinsonism. Arch Neurol 48, 361-363 (1991)

21.D.B. Calne: The free radical hypothesis in idiopathic parkinsonism: evidence against it. Ann Neurol 32, 799-803 (1992)

22.G. Fabrini, M.M. Mouradian, J.L. Juncos et al: Motor fluctuations in Parkinson's disease: central pathophysiologic mechanisms, Part I. Ann Neurol 24, 366-371 (1988)

23. M.R. Luquin, O. Scipioni, J Vaamonde et al.: Levodopa-induced dyskinesia in Parkinson's disease: clinical and pharmacological classification. Mov Disord 7, 117-124 (1992)

24.G.F. Wooten: Progress in understanding the pathophysiology of treatment related fluctuations in Parkinson's disease. Ann Neurol 24, 363-365 (1988) 